\title{
Effect of IgY on Periodontitis and Halitosis Induced by Fusobacterium nucleatum
}

\author{
Fang Wang ${ }^{1 \dagger}$, Wu Qiao ${ }^{2 \dagger}$, Bin Bao ${ }^{2}$, Shujun Wang ${ }^{3}$, Joe Mac Regenstein ${ }^{4}$, Yilei Shi ${ }^{5}$, Wenhui $\mathrm{Wu}^{2,6 *}$, and Ming Ma ${ }^{2,6 *}$ \\ ${ }^{1}$ Shanghai University of Medicine and Health Sciences, Shanghai, 201318, P.R. China \\ ${ }^{2}$ College of Food Science and Technology, Shanghai Ocean University, Shanghai 201306, P.R. China \\ ${ }^{3}$ Co-Innovation Center of Jiangsu Marine Bio-industry Technology, Huaihai Institute of Technology, Lianyungang, 222005, P.R. China \\ ${ }^{4}$ Department of Food Science, Cornell University, Ithaca, NY, 14853-7201, USA \\ ${ }^{5}$ Shanghai MAXAM Company Limited, Shanghai 200333, P.R. China \\ ${ }^{6}$ Laboratory of Quality and Safety Risk Assessment for Aquatic Products on Storage and Preservation (Shanghai), Ministry of Agriculture, \\ Shanghai 201306, P.R. China
}

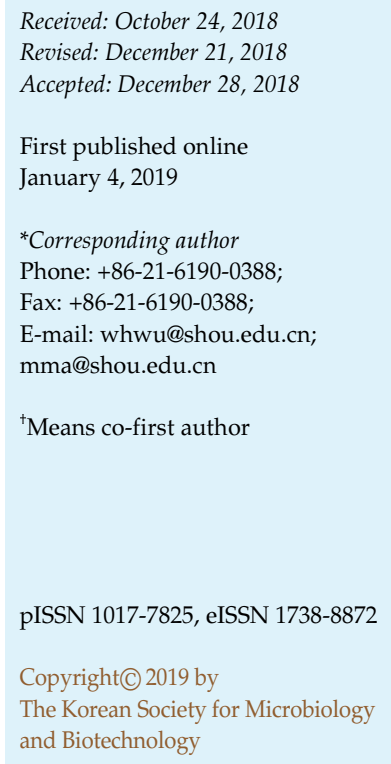

Fusobacterium nucleatum is a morbific agent in periodontitis and halitosis. Egg yolk antibody (IgY) was obtained from egg yolks from chickens stimulated with F. nucleatum. This study was to assess the effectiveness of IgY on periodontitis and halitosis caused by F. nucleatum in vitro and in vivo. The growth of F. nucleatum was inhibited $(p<0.05)$ by different concentrations of IgY in vitro and the results of a Halimeter show volatile sulfur compounds (VSCs) were reduced to $904 \pm 57 \mathrm{ppb}$ at a concentration $40 \mathrm{mg} / \mathrm{ml}$ of $\mathrm{IgY}$. The changes of fatty acids of F. nucleatum were determined using GC-MS. The scores for odor index of rat saliva were decreased. The major constituent of volatile organic compounds (VOCs) including short-chain acids decreased $46.2 \%$ in $10 \mathrm{mg} / \mathrm{ml} \mathrm{IgY,} \mathrm{ammonia} \mathrm{decreased} 70 \%$ in $40 \mathrm{mg} / \mathrm{ml} \mathrm{IgY,} \mathrm{while}$ aldehydes and olefine ketones were almost unchanged. The ELISA assay revealed that IL-6 and TNF- $\alpha$ were decreased after 4 weeks' IgY treatment. Morphometric (X-ray) and histological analyses (HE) showed that IgY reduced alveolar bone loss and collagen fibers became orderly in rat models. As a result, IgY may have the potential to treat periodontitis and halitosis.

Keywords: Egg yolk antibody, Fusobacterium nucleatum, halitosis, inflammation, alveolar bone loss

\section{Introduction}

Halitosis, a nasty odor emanating from the mouth, is a multi factorial disease. Bad breath is primarily related to volatile sulfur compounds (VSCs) including hydrogen sulfide (H2S) and methyl mercaptan that are produced by bacteria [1]. Moreover, butyric acid, methylamine, indole, dimethylamine, cadaverine, acetone and propionic acid are some other volatile organic compounds (VOCs) that may also contribute to oral malodor [2,3]. The main causes of bad breath are associated with tongue coating, and gingival as well as periodontal disease. Periodontitis is a chronic inflammatory disease of multifactorial etiology which is mainly caused by pathogenic bacteria. Periodontal disease can lead to pain and discomfort, impaired tissues of the teeth, and tooth loss [4]. The infection can spread and affect the entire periodontium, even causing cardiovascular disease [5]. While oral malodor is not directly caused by periodontal disease, abundant evidence indicates that periodontal disease intensifies the severity of malodor. According to the reports, approximately $60 \%$ of patients with periodontitis produce volatile sulfur compounds (VSCs) [6, 7].

Among oral bacteria, F. nucleatum is a Gram-negative anaerobe that has pathogenic potential and is involved in halitosis as well as periodontal diseases [8]. F. nucleatum is 
in a minority in the oral cavity, but is widely detected elsewhere in the body in case of infectious conditions [9]. F. nucleatum has strong invasive activity toward human gingival epithelial cells, and directly contributes to periodontal disease by forming a bridge with other virulent anaerobes [10]. Furthermore, F. nucleatum also produces large amounts of volatile sulfur compounds (VSCs) and is a representative bacterium in halitosis [1]. Available treatments, such as chemical antiseptics, antibiotics and mechanical therapy, are effectively used for halitosis and periodontitis. However, antibacterial-resistant bacteria and the by-effects of antibiotics limit antibacterial therapy [11]. Once treatments are discontinued, a simultaneous phenomenon becomes clearly apparent. F. nucleatum produces malodor during periodontitis development in the gums. To treat halitosis, the main strategy would reduce the components of oral malodor that are produced by microorganisms in the oral cavity.

Recently, chicken egg yolk antibody ( $\operatorname{IgY})$, which is obtained from the egg yolks of chickens immunized with distinctive antigens, has attracted much attention as a reliable and cost-effective immunotherapy method to prevent various diseases [12]. It was proved that IgY could be applied against caries caused by bacteria in rats [13], and it has been applied in human patients as well [14]. IgY can inhibit bacterial enzyme activity, neutralize toxins and decrease cell adhesion of microorganisms to reduce microbial infections. Anti-P. gingivalis egg yolk antibody, an immunotherapeutic agent, was verified to be powerful as a medication for periodontitis. Hamajima demonstrated that IgY suppresses the growth of biofilm on the tooth surface by binding a $40-\mathrm{kDa}$ outer membrane protein of Porphyromonas gingivalis [15]. IgY also inhibits the growth of Solobacterium moorei, a pathogenic agent in conditions like bad breath, periodontitis and other infections [16]. Xu et al. showed that IgY has a positively effective inhibition on F. nucleatum [17]. However, there are no studies on using IgY to remedy periodontal inflammation affiliated with halitosis caused by F. nucleatum. Therefore, this study investigated whether IgY extracted from the egg yolks of chickens treated with F. nucleatum has a positive effect in the treatment of halitosis and periodontitis caused by F. nucleatum.

\section{Materials and Methods}

\section{Bacterial Strain and Culture Conditions}

F. nucleatum (ATCC 25586) used in the present study was brought from American Type Culture Collection (Manassas, USA).
The bacteria were amplified in brain-heart infusion broth (Hopebio, Qingdao, China) adding $0.5 \mathrm{mg} / \mathrm{ml}$ of yeast extract (Hopebio, China), $1 \mu \mathrm{g} / \mathrm{ml}$ of menadione (Adamas, China) and $5 \mu \mathrm{g} / \mathrm{ml}$ of hemin (Adamas, China). Modified artificial saliva (AS) was prepared following the instructions of Pratten et al. and Wong $\mathrm{L}$ et al. [18]. AS was used to culture F. nucleatum in anaerobic environment at $37^{\circ} \mathrm{C}$ using an anaerobic pack (Mitsubish, Japan) without shaking.

\section{The Growth Inhibition of $F$. nucleatum}

The growth inhibition assay was performed according to the previous method [19]. After amplifying in BHI media, the F. nucleatum was harvested by centrifugation and adjusted to a final concentration at an OD of $650 \mathrm{~nm}$ of $0.5\left(10^{\wedge} 9 \mathrm{CFU} / \mathrm{ml}\right)$ in the AS. IgY against $F$. nucleatum (extracted from egg yolks after chickens were challenged with $F$. nucleatum) obtained from Maxam Ltd. (China). IgY was reconstituted to 40 (high-dose), 20 (mid-dose), 10 (low group) $\mathrm{mg} / \mathrm{ml}$ in $3.9 \mathrm{ml}$ liquid medium. Prepared AS that is free of IgY was used as negative and blank control. $200 \mathrm{ul} \mathrm{F.nucleatum} \mathrm{liquid} \mathrm{containing} 1.8 \mathrm{ml}$ of AS and bacterial solutions were incubated at $37^{\circ} \mathrm{C}$ in an anaerobic environment. Aliquots of bacteria $(2 \mathrm{ml})$ were taken at $0,2,4$, and $6 \mathrm{~h}$ in sterile tubes, and absorbance was measured at $650 \mathrm{~nm}$ using a spectrophotometer (V5100B, METASH Ltd., China).

\section{VSC Measurement with Halimeter}

The bacteria were cultured in a $2 \mathrm{ml}$ glass bottle containing AS media with different concentrations of IgY. The air above the medium in the bottle was analyzed. The changes in the VSCs were assessed using the Halimeter (Interscan Corp., USA), which is a sulfide monitor. F. nucleatum mingled with different concentrations of IgY and artificial saliva was incubated at $37^{\circ} \mathrm{C}$ for $48 \mathrm{~h}$ using an anaerobic pack (Mitsubishi, Japan) without shaking. Then a new $0.25 \mathrm{~cm}$ plastic straw was inserted into the air inlet of the Halimeter and another end of the plastic straw was attached to the test tubes headspace to measure levels of VSC. The values for three parallel maximum readings in parts per billion $(\mathrm{ppb})$ were recorded [20].

\section{Measurement of Fatty Acids in Media}

In order to detect fatty acids, the artificial saliva needs to be concentrated. The media were filtered through a Poly-Sery HLB solid phase extraction (SPE) column (CNWBOND HC-C18, Anpel, China), and washed thoroughly with $1 \mathrm{ml}$ methanol (CNW HPLCgrade, Anple, China). Then the liquid was transferred to a $1.5-\mathrm{ml}$ tube for analysis of fatty acids. An Aglilent 7890A was used as a chromatography solution system (Agilent, USA) supplied with a HP-5 MS capillary column (30 m $\times 250 \mu \mathrm{m} \times 0.25 \mu \mathrm{m}$; crosslinked (5\% -phenyl) -methylpolysiloxane; Agilent Scientific, Folsom, USA). The sample $(2 \mu \mathrm{l})$ was injected with a 25 -ul syringe (Shanghai Guangzheng Medical Instrument Co.) A split ratio was set at 1:1. Helium was used as a carrier gas and the constant flow rate was set at $1 \mathrm{ml} / \mathrm{min}$. The inlet temperature was set at $250^{\circ} \mathrm{C}$ 
and the GC column temperature rose to $285^{\circ} \mathrm{C}$ at a rate of $8^{\circ} \mathrm{C} / \mathrm{min}$ and then maintained at $285^{\circ} \mathrm{C}$ for $5 \mathrm{~min}$. The AMSD 5973 massspectrometer was set on ion monitoring mode and focused at $\mathrm{m} / \mathrm{z}$ 40-400 molecular ion. The temperature of the source was $230^{\circ} \mathrm{C}$. Mass spectra were obtained at an energy level of $70 \mathrm{eV}$. The structure of the sample was identified by the National Institute of Standards and Technology (NIST) library. According to the software provided by the instrument, the interference peak is removed, then the chemicals are integrated. The proportion of the different components relative contention $\left(\mathrm{Ab}^{*} \mathrm{~s}\right)$ is calculated.

\section{Establishment of Periodontitis Rat Model}

Specific-pathogen-free female Sprague Dawley (SD) rats $(n=10$, weight $150 \mathrm{~g} \pm 10 \mathrm{~g}$ ) were purchased form SLA Laboratory Animal Co., Ltd (China). Rats were fed in individual cages and afforded sterile food and water under specific-pathogen-free condition. Rats are used for experiments when they are 9-10 weeks old and they are handled according to guidelines set by the Ethics Committee of Shanghai Ocean University (China). For establishment of a halitosis with periodontitis rat model, maxillary bilateral second molar of the rats were ligatured with a sterile 5-0 silk (Sangon Biotech Co., Ltd., China). Then $100 \mu$ l live F. nucleatum $\left(10^{\wedge} 8 \mathrm{CFU} / \mathrm{ml}\right)$ mixed in PBS was smeared into each rat's oral cavity three times a week and lasting four weeks to induce periodontal infection. After successful modeling, the diseased rats were divided into three groups $(n=3)$ randomly and given different treatments. In the experimental groups, $200 \mu \mathrm{l}$ of different concentrations of IgY solutions were smeared one times into the oral cavity every day for 30 days. The same volume of $0.9 \% \mathrm{NaCl}$ solution served as a negative control.

\section{Organoleptic Measurements}

Two experienced odor judges assessed malodor levels, as previously reported [21]. Judging scores were recorded on a range of 0 to 5 , as follows: score 0 , no distinct odor; score 1 , almost no noticeable malodor; score 2 , minor, but clearly notable malodor; score 3, mild malodor; score 4, strong malodor; score 5, extremely intensive malodor. The saliva was obtained by sterile cotton swabs wiping for $30 \mathrm{sec}$ in the oral cavity of the rats from each treatment. The swabs were placed immediately into a $10-\mathrm{ml}$ headspace vial with a screw top lid (CNW, Anple, China). Judges immediately sniffed the malodor emanating from each test tube to assess malodor levels.

\section{Measurement of Malodor Compounds from Rat Saliva}

The new collection of saliva samples were placed into vials and placed in a water bath adjusted to $45^{\circ} \mathrm{C}$. Three replicates per each sample were prepared and analyzed. After $30 \mathrm{~min}$, headspace VOCs were volatilized and adsorbed on a SPME fiber $(65 \mu \mathrm{m}$, PDMS/DVB; Anpel, China). SPME fiber was desorbed at $250^{\circ} \mathrm{C}$ for $5 \mathrm{~min}$ in the injector port of a GC connected with a mass detector with a scan range from 40 to 400 . The initial column temperature was set at $50^{\circ} \mathrm{C}$, then ascended at $10^{\circ} \mathrm{C} / \mathrm{min}$ to $150^{\circ} \mathrm{C}$ then $5^{\circ} \mathrm{C} / \mathrm{min}$ to $250^{\circ} \mathrm{C}$ and maintained for $2 \mathrm{~min}$. The conditions of MS followed the above.

\section{IgY Effect on Levels of IL-6 and TNF- $\alpha$}

Heart blood was collected from the groups after 4 weeks' different treatment. After centrifugation at $12,000 \times g$ for $8 \mathrm{~min}$, the supernatants were transferred to a new tube. According to the manufacturer's instructions, we used enzyme-linked immunosorbent assay kits (ELISA) (Mlbio, China) to measure the concentration of TNF- $\alpha$ and IL-6. All samples were measured in triple repetition with provided standards. The ELISA wells were examined using a microplate reader (SH-100, USA) at a wavelength of $450 \mathrm{~nm}$.

\section{Histopathological Analysis}

After collecting blood samples, the maxillary molar regions of the rats were resected from each rat and fixed in $4 \%$ paraformaldehyde sodium phosphate buffer for $36 \mathrm{~h}$. Radiographic images of the maxillary were taken by an X-ray machine (Faxitron MX-20 DC12 system; 119 Faxitron Bioptics, Lincolnshire, USA). The bilateral mandibles were demineralized in formic acid (10\%) at room temperature for one week. Then bilateral mandibles were embedded in paraffin; bilateral mandibles were cut into $4-\mu \mathrm{m}$ thick sections using a microtome (Leica RM2235, Germany). Samples were stained with hematoxylin and eosin according to H\&E protocol using light microscopy (Lecia, Germany) to observe histopathology.

\section{Statistical Analysis}

Statistical analysis was performed using SPSS 18.0 ((SPSS Inc., USA). All data were represented as means \pm standard deviation (S.D.) and were analyzed using Student's $t$-tests. $P<0.05$ was considered statistically significant.

\section{Results}

\section{Growth Inhibition of IgY to F. nucleatum In Vitro}

To examine the capability of IgY to inhibit growth of F. nucleatum in artificial saliva, we cultured bacteria in the tubes adding different concentrations of IgY for $0,2,4$, and $6 \mathrm{~h}$. Growth curves of F. nucleatum in media with $\mathrm{IgY}$ concentrations of high-dose $(40 \mathrm{mg} / \mathrm{ml})$, mid-dose $(20 \mathrm{mg} / \mathrm{ml})$, low-dose $(10 \mathrm{mg} / \mathrm{ml})$ and blank are shown in Fig. 1. After adding IgY, the turbidity of media decreased. The phenomenon mainly stems from the fact that F. nucleatum increased after the treatment with IgY. In these cases, growth was significantly inhibited by the addition of highdose specific IgY $(p<0.01)$ compared with the control group. $10 \mathrm{mg} / \mathrm{ml}$ (low-dose) and $40 \mathrm{mg} / \mathrm{ml}$ (mid-dose) groups had less of a decrease in bacterial counts than the high-dose one. The capability of $10 \mathrm{mg} / \mathrm{ml}$ (low-dose) group to inhibit growth is similar to $20 \mathrm{mg} / \mathrm{ml}$ (mid-dose) $(p<0.05)$ compared with the control group. 


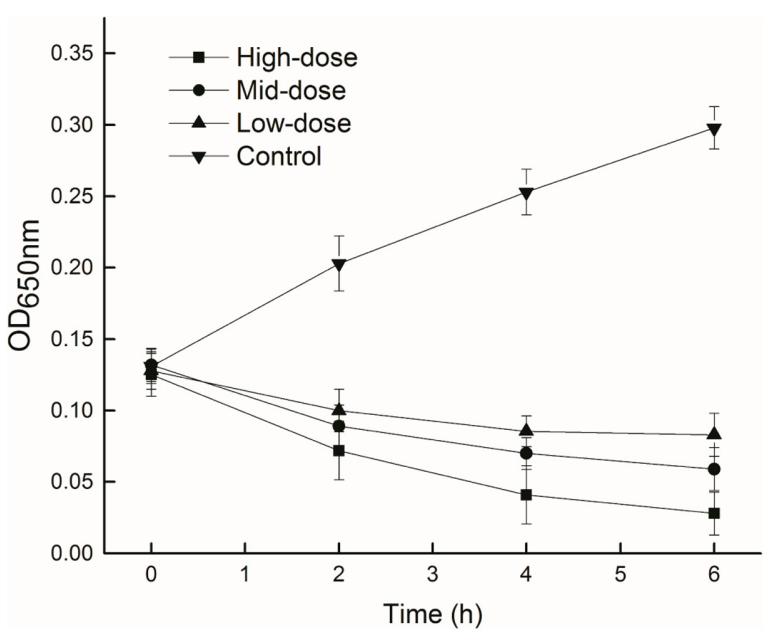

Fig. 1. The inhibitory effect of IgY on the growth of F. nucleatum.

F. nucleatum were incubated in artificial saliva medium with high-

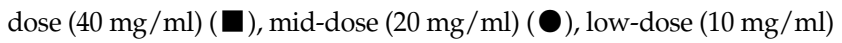
$(\boldsymbol{\Delta})$ and blank control ( $\boldsymbol{\nabla})$. Experience data are represented as mean \pm S.D. of three individual experiments. ${ }^{*}$ Means $p<0.05$, and ${ }^{* *}$ means $p<0.01$ as compared with the control.

\section{The Inhibition of VSCs by IgY}

Halimeter is an effective instrument that measures total breath VSCs by electrochemical sensors. VSC production by F. nucleatum was measured in the process of different doses of IgY. As shown in Table 1, the concentration of IgY was related to the production of VSCs. More specific, high-dose IgY was associated with the production of $904 \pm 57 \mathrm{ppb}$ compared to $1,921 \pm 99 \mathrm{ppb}$ in the absence of IgY. In other words, there is a significant trend of decreasing after adding the high-dose IgY $(p<0.01)$. Supplementing the culture medium with mid-dose IgY and low-dose IgY only slightly decreased VSCs levels produced by F. nucleatum. The inhibition effect increased as the concentration of specific IgY increased in the range of medium to high concentrations. The effect of mid-dose IgY

Table 1. The VSC production by F. nucleatum in different concentrations of IgY.

\begin{tabular}{lcc}
\hline \multicolumn{1}{c}{ Groups } & $\begin{array}{c}\text { Halimeter } \\
(\text { mean mean } \pm \mathrm{SD}, \mathrm{ppb})\end{array}$ & $P$-value \\
\hline Control & $1,921 \pm 99$ & \\
High-dose IgY & $904 \pm 57$ & $<0.01^{* *}$ \\
Mid-dose IgY & $1,233 \pm 52$ & $<0.05^{*}$ \\
Low-dose IgY & $1,340 \pm 44$ & $<0.05^{*}$ \\
\hline
\end{tabular}

Experience data are represented as mean \pm S.D. of three individual experiments.

${ }^{*}$ Means $p<0.05$, and ${ }^{* *}$ means $p<0.01$ compared with the control.

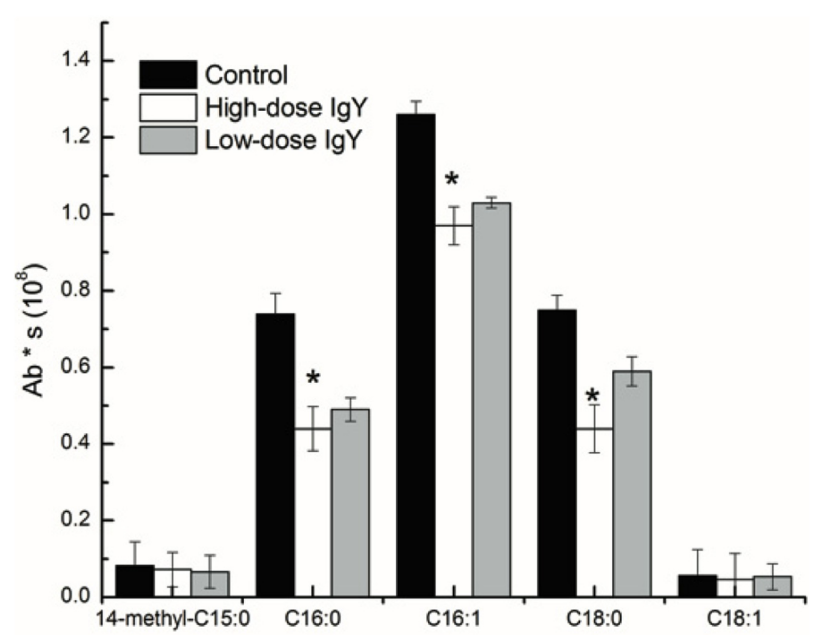

Fig. 2. The fatty acids of different concentrations of IgY in artificial saliva.

Experience data are represented as mean \pm S.D. of three individual experiments. ${ }^{*}$ Means $p<0.05$, and ${ }^{* *}$ means $p<0.01$ compared with the control.

on inhibiting VSCs is almost the same as that of low concentration.

\section{The Changes of Fatty Acids In Vitro by IgY}

Fatty acids produced by microbial metabolism are significant characteristics in species and quantities. Most bacterial acids are bounded with arguer molecules, such as phospholipids, glycolipids. Free acids, which are extracted with solvents, are found by GC-MS. The long-chain fatty acids were detected by GC-MS. C16:0, C16:1, and C18:0, the main components from the metabolic production of F. nucleatum in the artificial saliva, accounted for about $80 \%$ in fatty acids. No marked differences were found between control group and IgY groups regarding C18:1. The results indicate that the relative content of C16:1 decreased 28.6\% compared with the control in Fig. 2. Trace amounts of 14methyl-C15:0 were detected in artificial saliva. The percentage of C18:0 and C16:0 significantly decreased $(p<0.05)$ after the treatment of high-dose IgY.

\section{The Changes of Odor Index}

When F. nucleatum was incubated orally in mice, the odor judges' scores were high. Furthermore, the addition of high-dose $\operatorname{IgY}(40 \mathrm{mg} / \mathrm{ml})$ to the rat orally significantly lowered both judges scores (Fig. 3) $(p<0.05)$, as compared with the blank control. In the presence of $10 \mathrm{mg} / \mathrm{ml} \mathrm{IgY,}$ malodor production was higher than high-dose $\operatorname{IgY,~but~}$ judge scores were lower than blank control $(p<0.05)$. 


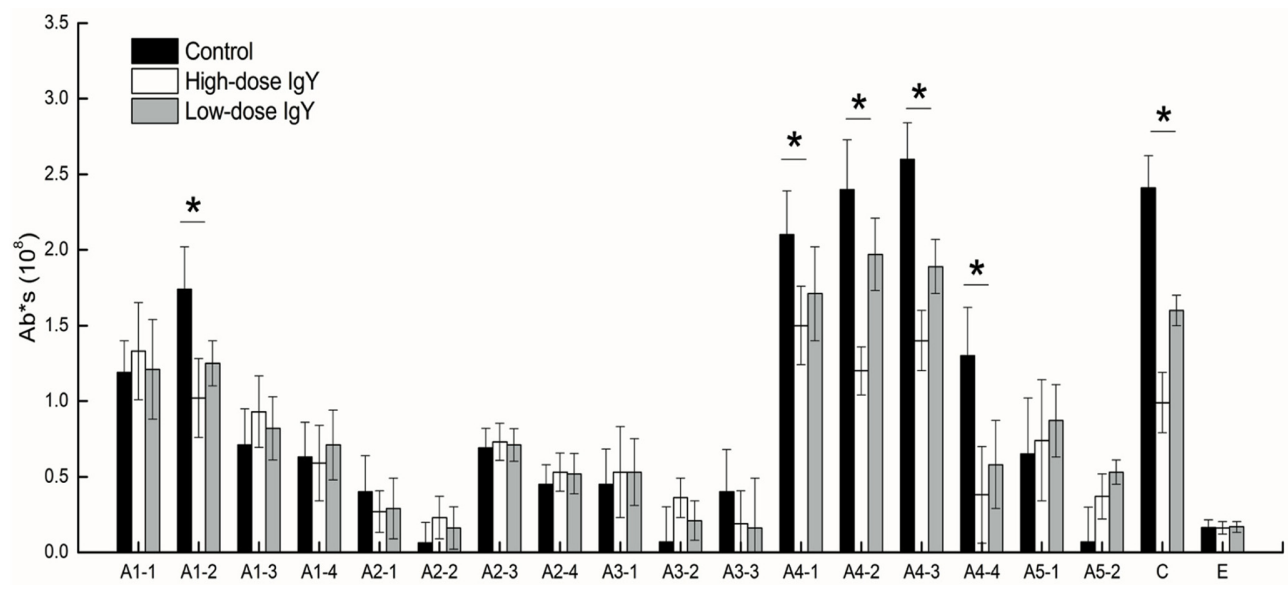

Fig. 3. The effect of IgY on rat malodor induced by F. nucleatum.

Mean \pm S.D. of malodor levels as scored by two judges (with results presented on a semi-integer scale of $(0-5)$ of three individual experiments. ${ }^{*}$ Means $p<0.05$.

\section{The Changes of Volatile Organic Compounds (VOCs) In Vivo by IgY}

The Halimeter does not record all the odor vectors present in the breathed air. Volatile organic compounds (VOCs) in saliva of animal models were detected using SPME-GCMS. A total of 17 compounds were found to be ubiquitous in all samples in the present study, which included 4 alcohols, 4 carboxylic acids, 3 ketones, 2 aldehydes, 2 esters and 1 nitrogen compound (Table 2). According to the previous literature, all the compounds were divided into six categories. A1 represents alcohol, A2 represents aldehydes,

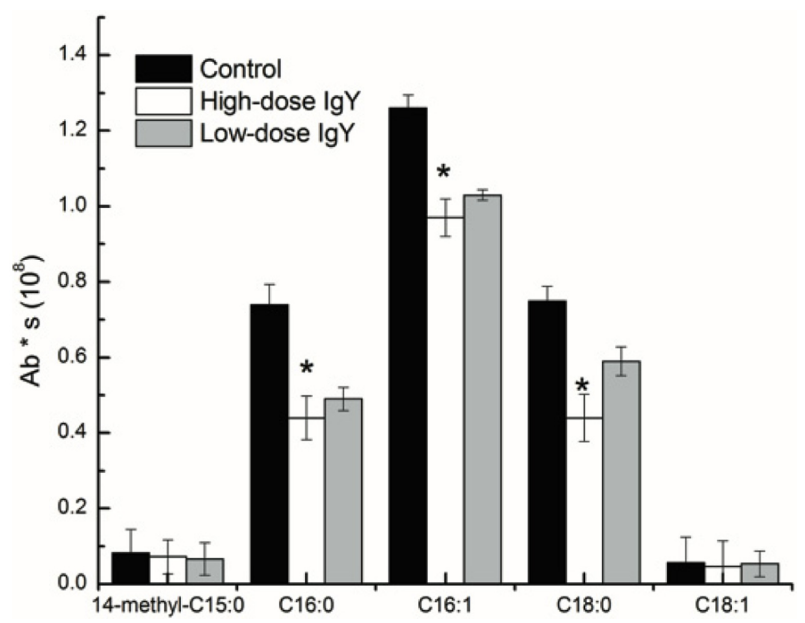

Fig. 4. The decrement of VOCs from oral saliva samples of rats by GC-MS analysis.

Experience data are represented as mean \pm S.D. of three individual experiments. ${ }^{*}$ Means $p<0.05$, and ${ }^{* *}$ means $p<0.01$ compared with the control.
A3 represents ketone, A4 represents carboxylic acid, A5 represents ester, $\mathrm{C}$ represents nitrogen compounds. These VOCs are dominant classes of organic volatiles represented in the microbial production and release of chemicals. The proportion of different components relative contention $\left(\mathrm{Ab}^{*} \mathrm{~s}\right)$ changes as shown in Fig. 4. Short-chain acids account for the largest proportion, with butyric acid accounting for about $13 \%$ of short-chain acids. After treatment of IgY, butyric acid, hexanoic acid, propionic acid and acetic acid are significantly reduced $(p<0.05)$. Another important substance, ammonia $(C)$, is decreased by high-dose $(40 \mathrm{mg} / \mathrm{ml})$ and low-dose $(10 \mathrm{mg} / \mathrm{ml}) \mathrm{IgY}$. The high decrements of abundances contain short-chain acids, ammonia and alcohol, which indicates that these ingredients are sensitive in volatile odors. High-dose IgY significantly decreased ingredients that have a pungent smell, low-dose IgY decreased the amount of reduction is less than high-dose IgY (Fig. 4). However, aldehydes (A2) and ketone (A3) were almost unchanged in the negative control.

\section{IgY Effect on Levels of IL-6 and TNF- $\alpha$}

To evaluate the response of F. nucleatum stimulation on rats' TNF- $\alpha$ and IL-6, rat oral cavity was incubated with F. nucleatum. After treatment with different concentrations of IgY, IL- 6 and TNF- $\alpha$ were assessed by ELISA. The levels of the anti-inflammatory cytokine were higher in the control group compared to IgY-treated subjects after 4 weeks' treatment. As shown in Fig. 5, the concentration of TNF- $\alpha$ and IL- 6 after the treatment of $10 \mathrm{mg} / \mathrm{ml}$ (low-dose) were significantly decreased $(p<0.05)$ compared with 
Table 2. Composition of VOCs of rat saliva.

\begin{tabular}{|c|c|c|c|c|c|}
\hline No. & Retention time & CAS & Name & Structure & Classification \\
\hline 1 & 1.4 & $7664-41-7$ & Ammonia & $\mathrm{NH}_{3}$ & Nitrogen compounds (C) \\
\hline 2 & 1.9 & $926-65-8$ & 2-Propane & & Others (E) \\
\hline 3 & 2.3 & $64-19-7$ & Acetic acid & & Carboxylic acid (A4-1) \\
\hline 4 & 3.8 & $71-41-0$ & Pentanol & & Alcohol (A1-1) \\
\hline 5 & 4.9 & 79-09-4 & Propionic acid & & Carboxylic acid (A4-2) \\
\hline 6 & 6.1 & $66-25-1$ & Hexanal & & Aldehyde (A2-1) \\
\hline 7 & 8.1 & $107-92-6$ & Butyric acid & & Carboxylic acid (A4-3) \\
\hline 8 & 9.1 & $111-27-3$ & n-Hexanol & & Alcohol (A1-2) \\
\hline 9 & 13.7 & $3391-86-4$ & 1-Octen-3-ol & & Alcohol (A1-3) \\
\hline 10 & 14.6 & $110-93-0$ & Methyl isohexenyl ketone & & Ketone (A3-1) \\
\hline 11 & 15.1 & $124-13-0$ & Octyl aldehyde & & Aldehyde (A2-2) \\
\hline 12 & 15.5 & $142-62-1$ & Hexanoic acid & & Carboxylic acid (A4-4) \\
\hline 13 & 16.4 & $104-76-7$ & Isooctyl Alcohol & & Alcohol (A1-4) \\
\hline 14 & 17.5 & $2548-87-0$ & Trans-2-Octen-1-al & & Aldehyde (A2-3) \\
\hline 15 & 18.3 & $695-06-7$ & Gamma-hexalactone & & Ester (A5-1) \\
\hline 16 & 23.1 & $112-31-2$ & Decyl aldehyde & & Aldehyde (A2-4) \\
\hline 17 & 25.4 & $927-49-1$ & 6-Undecanone & & Ketone (A3-2) \\
\hline 18 & 26 & $540-07-8$ & Amyl caproate & & Ester (A5-2) \\
\hline 19 & 28 & $6064-27-3$ & Dodecan-6-one & & Ketone (A3-3) \\
\hline
\end{tabular}




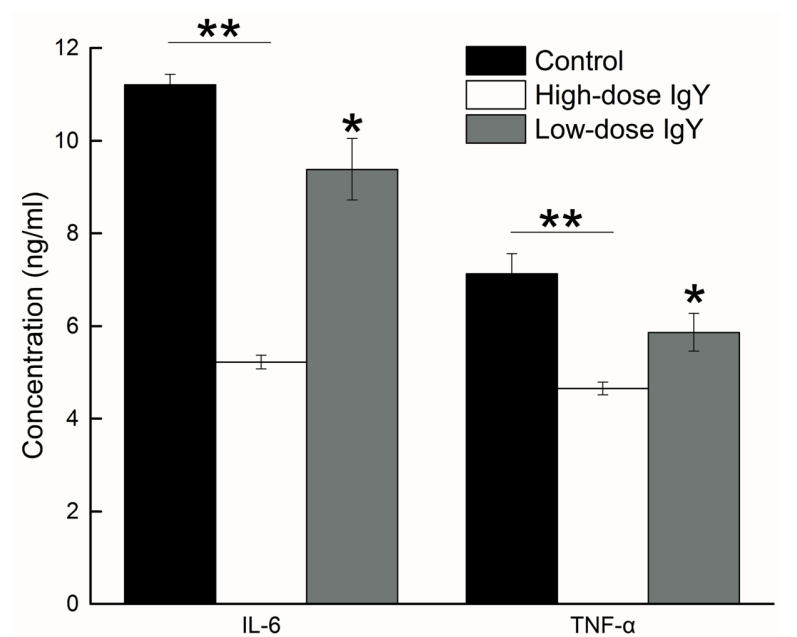

Fig. 5. The changes of TNF- $\alpha$ and IL-6 in rat serum.

Experience data are represented as mean \pm S.D. of three individual experiments. ${ }^{*}$ Means $p<0.05$, and ${ }^{* *}$ means $p<0.01$ compared with the control. The concentrations of TNF- $\alpha$ and IL- 6 in $10 \mathrm{mg} / \mathrm{ml}$ (low-dose) were significantly $(p<0.05)$ decreased compared with control. The concentration of IL-6 in high-dose was lower than control $(p<0.01)$.

control group. IL-6 reduced from $11.2 \mathrm{ng} / \mathrm{ml}$ to $5.3 \mathrm{ng} / \mathrm{ml}$ at high dose IgY and TNF- $\alpha$ reduced from $7.3 \mathrm{ng} / \mathrm{ml}$ to $4.7 \mathrm{ng} / \mathrm{ml}$. The concentration of IL-6 quite significantly $(p<0.01)$ decreased in high-dose group, and the level of TNF- $\alpha$ was significantly $(p<0.01)$ lower than control group, and the level of TNF- $\alpha$ was markedly $(p<0.01)$ lower than control group. Additionally, it was obvious that low-dose IgY groups reduced the IL- 6 and TNF- $\alpha$ levels by about $7 \%$ and $9.6 \%$ compared to the level in the negative group.

\section{Alveolar Bone Loss and Histopathological Analysis}

The mouse model of periodontitis caused by F. nucleatum infection was used to investigate the effect of IgY. The results of $X$-ray and histological examination by $H \& E$ staining were showed in Fig. 6. The results of X-ray showed that the gap between the teeth of the control group is large and the alveolar bone has a large gap between the teeth. After four weeks treatment of high-dose IgY, the gaps between teeth significantly reduce and alveolar bone is close to teeth. As shown in Fig. 6B, there is a clear trend of decreasing alveolar bone resorption after different concentration of IgY. Moreover, disorganization of the connective tissue and remarkable inflammatory infiltration and were observed in Fig. 6C. Effective rehabilitation of periodontium, including restoration of collagen fibers was detected in Fig. 6C. After 4-weeks' treatment, high-dose $(40 \mathrm{mg} / \mathrm{ml}) \mathrm{IgY}$ significantly improved periodontal restoration.

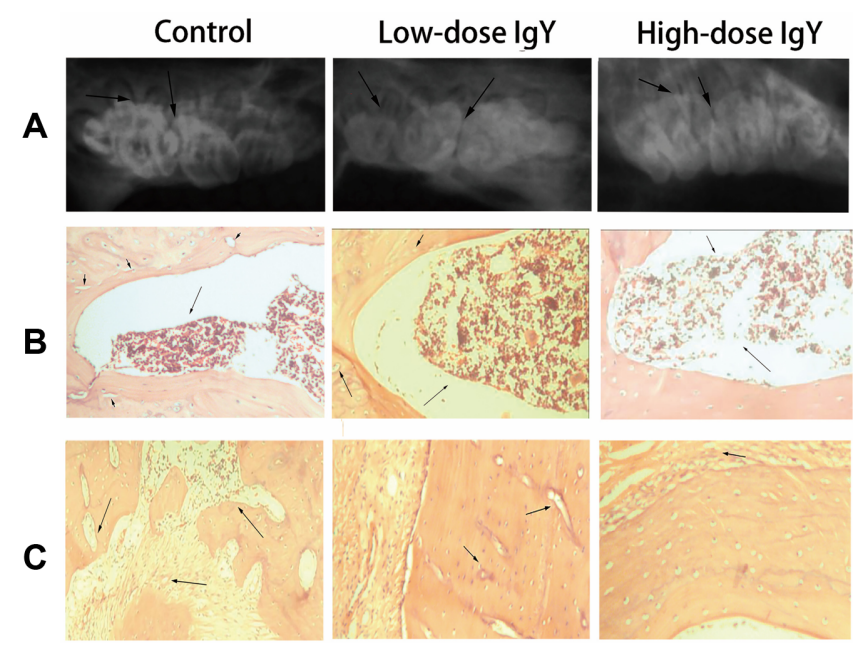

Fig. 6. The influence of $\operatorname{IgY}$ on alveolar bone loss and periodontium restoration in periodontitis rats.

(A) Representative X-ray images of alveolar bone in the rats. Black arrows indicate the gap between alveolar bone and teeth. (B) HE stains of the region that contains the first and the second upper molars. Black arrows indicate alveolar (C) HE stains of the periodontium. Black arrows indicate collagen fibers.

\section{Discussion}

Many in vitro studies have investigated that specific IgY has antimicrobial activity against a series of oral bacteria, such as Salmonella enteritidis [22], F. nucleatum [23]. Most research only investigated the inhibition of fungicide and metal ion in general medium. Saliva contains a complex mixing of protein, vitamin and ion, but the acquisition of saliva needs many volunteers and saliva has less reproducibility. In this in vitro study, the artificial saliva that has the similar components with natural saliva was used to simulate the human saliva that F. nucleatum grows in the oral cavity. With artificial saliva, it is easy to control macromolecular, ion and amino acids of the medium to manipulate their effect on F. nucleatum growth and metabolism [18]. In this study, specific IgY significantly reduced the amount of F. nucleatum (Fig. 1). The IgY targeted 40-kDa outer membrane protein of $P$. gingivalis has been proved that IgY can significantly inhibit the coaggregation of $P$. gingivalis with other bacteria [15]. Thus, IgY may effectively bind cell surface components including outer membrane proteins or lipopolysaccharides to inhibit $F$. nucleatum growth [17]. The cell membrane fatty acid of Fusobacteria strains contains C14:0, C16:0, and cis-9 C16:1 which are the primary fatty acids [24]. In this study, IgY reduces the amount of fatty $\mathrm{C} 16: 0, \mathrm{C} 16: 1$, and C18:0, which 
may indicate that IgY acts on the metabolism of fatty acids to inhibit F. nucleatum. At the same time, the changes of short-chain fatty acids in saliva may also be related to the reduction of long-chain fatty acids.

VSCs compounds including $\mathrm{H} 2 \mathrm{~S}$ and $\mathrm{CH} 3 \mathrm{SH}$ dominate halitosis [25]. After the treatment of IgY, odor index significantly decreased, which indicates IgY prevents halitosis in vivo (Fig. 4). After the treatment of IgY, odor index significantly decreased, which indicates IgY prevents halitosis in vivo (Fig. 4). Bacterial enzymes, L-cysteine desulfhydrase and METase, produce VSCs by digesting amino acids [26]. However, many amino acid catabolic enzymes are situated in bacteria, which render antibodies unable to efficiently affect them. Inhibition of microbial growth by antibodies is another effective alternative method. In our study, IgY was able to significantly reduce VSCs by inhibiting the growth of bacteria. Zinc ions have two mechanisms of malodor inhibition by binding with $\mathrm{H}_{2} \mathrm{~S}$ and antimicrobial activity [27]. According to the reports, F. nucleatum produces VSC, which is related with Cdl (Fn1220) and Lcd (Fn0625) [28]. Cetylpyridinium chloride (CPC) has been found to impress the cdl expression in F. nucleatunm. Meanwhile, CPC induces lcysteine desulfhydrase expression [29]. IgY may influence the expression of VSC-related gene which was speculated.

This study used live F. nucleatum to imitate halitosis and periodontitis in mice oral cavity. In oral cavity, VSCs are one of the sources of bad breath; VOCs also are important parts of halitosis. VOCs in breath dissolve in saliva influencing its composition. Human saliva contains complex composition including peptides, proteins, and numerous volatile organic compounds. Various oral bacteria use different systems to degrade nutrients that produces various volatile organic compounds (VOCs). Several studies have investigated the volatile organic compounds in saliva. They reported that the presence of six types of compounds ketones, alcohols, aldehydes, aldehydes, esters and volatile acids [30]. The changes of salivary VOC composition may be an excellent indicator of halitosis through the treatment of IgY. Short-chains alcohols, ketones and esters are detected in our research. The methods of saliva collection also may influence its composition. So, a non-stimulated saliva collection approach was chosen in this study to avoid influence. Although rat oral cavity is different from human, the changes of VOCs are similar to human. After the treatment of IgY, odor index significantly decreased, which indicates IgY prevents halitosis. Volatile acids have a stimulating odor. IgY effectively inhibits halitosis by reducing part of the ingredients of VOCs. The model of rat may provide an effective method for development of antihalitosis and anti-periodontitis drugs or antibodies in the future.

In this model, mechanical trauma caused by ligature destroys the integrity of tissue to induce an inflammatory response and periodontal ligament, which induces serious bone loss [32]. In vivo study, periodontitis rat without IgY treatment have significant bone loss compared with IgY treatment, accompanying collagen fiber disorder. Prior studies have noted that the anti-P. g IgY in the periodontitis disease could decrease the probing depth [33]. There are macrophages in dental pulp that are activated by TNF- $\alpha$ $[34,35]$. Anaerobic bacteria produce many metabolic end products including short-chain fatty Acids. Secondly, volatile acids (e.g., butyric, acetic, isovaleric and propionic) are important parts of halitosis. Butyric and propionic acids have been proved that they have cytotoxicity to vero cells [36]. In this study, butyric acid, propionic acid and caproic acid are detected using SPE-GC-MS. Butyric acid is one of the major by-products of F. nucleatum. Butyric acid also can inhibit T-cell proliferation and stimulate the monocytes and neutrophils to produce proinflammatory cytokines [37] which increase the severity of periodontitis and halitosis. Our study is in agreement with previous studies that increased cytokine IL- 6 and TNF- $\alpha$ in response to F. nucleatum [38]. Specific IgY targeting to F. nucleatum significantly inhibit cytokine, which may be related to the reduction of butyric acid.

In conclusion, IgY induces systemic immune responses to F. nucleatum and VSCs in a dose-dependent manner in vitro. SPE-GC-MS revealed that specific IgY possibly acts on mechanisms of F. nucleatum. The IgY has an effective impact on periodontal and halitosis disease caused by F. nucleatum in rat, which was further proved by its ability to decrease alveolar bone loss, inflammation and VOCs. F. nucleatum has also been involved in the pathogenesis of several diseases [39]. Most important, the study provides an effective strategy for the treatment of disease caused by F. nucleatum. 


\section{Acknowledgment}

The authors acknowledge the funding support received from the National Natural Science Foundation of China (Project Grant No. 81750110548), an International Young Scientist Research Fellowship, the National High Technology Research and Development Program of China (Project Grant No. 2011AA09070109), and the Plan of Innovation Action in Shanghai (Project Grant No. 15410722500 and 17490742500).

\section{Conflict of Interest}

The authors declared that they have no conflicts of interest in this work.

\section{Reference}

1. Amou T, Hinode D, Yoshioka M, Grenier D. 2014. Relationship between halitosis and periodontal disease - associated oral bacteria. Int. J. Dent. Hyg. 12: 145-151.

2. Goldberg S, Kozlovsky A, Gordon D, Gelernter I. Sintov A, Rosenberg M. 1994. Cadaverine as a putative component of oral malodor. J. Dent. Res. 73: 1168-1172.

3. Phillips M, Herrera J, Krishnan S, Zain M, Greenberg J, Cataneo RN. 1999. Variation in volatile organic compounds in the breath of normal humans. J. Chromatogr. B. Biomed. Sci. Appl. 729: 75-88.

4. Oh TJ, Eber R, Wang HL. 2002. Periodontal diseases in the child and adolescent. J. Clin. Periodontol. 29: 400-410.

5. Kolenbrander PE, Andersen RN, Blehert DS, Egland PG, Foster JS, Palmer RJ Jr. 2002. Communication among oral bacteria. Microbiol. Mol. Biol. Rev. 66: 486-505.

6. Sato H, Ohkushi T, Kaizu T, Tsunoda M, Sato T. 1980. A study of the mechanism of halitosis occurrence in periodontal patients. Bul. Tokyo Dent. Coll. 21: 271-278.

7. Yaegaki K, Sanada K. 1992. Biochemical and clinical factors influencing oral malodor in. periodontal. J. Periodontol. 63: 783-789.

8. Kang MS, Kim BG, Chung J, Lee HC, Oh JS. 2006. Inhibitory effect of Weissella cibaria isolates on the production of volatile. J. Clin. Periodontol. 33: 226-232.

9. Signat B, Roques C, Poulet P, Duffaut D. 2011. Fusobacterium nucleatum in periodontal health and disease. Curr. Issues. Mol. Biol. 13: 25-36.

10. Han YW, Shi W, Huang GT, Kinder Haake S, Park NH, Kuramitsu $\mathrm{H}$, et al. 2000. Interactions between periodontal bacteria and human oral epithelial cells. Infect. Immun. 68: 3140-3146.

11. Handal T, Caugant DA, Olsen I. 2003. Antibiotic resistance in bacteria isolated from subgingival plaque in a norwegian population with refractory marginal periodontitis. Antimicrob. Agents Chemother. 47: 1443-1446.

12. Lu Y, Liu J, Jin L. 2009. Passive immunization of crayfish (Procambius clarkiaii) with chicken egg yolk. Appl. Biochem. Biotechnol. 159: 750-758.

13. Otake S, Nishihara $Y$, Makimura M, Hatta H, Kim M, Yamamoto T, et al. 1991. Protection of rats against dental caries by passive immunization with hen-egg-yolk antibody (IgY). J. Dent. Res. 70: 162-166.

14. Hatta H, Tsuda K, Ozeki M, Kim M, Yamamoto T, Otake S, et al. 1997. Passive immunization against dental plaque formation in humans: effect of a mouth rinse containing egg yolk antibodies (IgY) specific to Streptococcus mutans. Caries Res. 31: 268-274.

15. Hamajima S, Maruyama M, Hijiya T, Hatta H, Abiko Y. 2007. Egg yolk-derived immunoglobulin (IgY) against Porphyromonas gingivalis $40-\mathrm{kDa}$ outer membrane protein inhibits coaggregation activity. Arch. Oral Biol. 52: 697-704.

16. Li X, Liu H, Xu Y, Xu F, Wang L, You J, et al. 2012. Chicken egg yolk antibody $(\operatorname{Ig} Y)$ controls Solobacterium moorei under in vitro and in vivo conditions. Appl. Biochem. Biotechnol. 168: $1448-1458$

17. Xu FX, Xu YP, Jin LJ, Liu H, Wang LH, You JS, et al. 2012. Effectiveness of egg yolk immunoglobulin (IgY) against periodontal. J. Appl. Microbiol. 113: 983-991.

18. Wong L, Sissons C. 2001. A comparison of human dental plaque microcosm biofilms grown in an undefined medium and a chemically defined artificial saliva. Arch. Oral Biol. 46: 477-486.

19. He Z, Huang Z, Zhou W, Tang Z, Ma R, Liang J. 2016. Antibiofilm activities from resveratrol against Fusobacterium nucleatum. Front. Microbiol. 7: 1065.

20. Furne J, Majerus G, Lenton P, Springfield J, Levitt DG, Levitt MD. 2002. Comparison of volatile sulfur compound concentrations measured with a sulfide detector vs. gas chromatography. J. Dent. Res. 81: 140-143.

21. Greenman J, El-Maaytah M, Duffield J, Spencer P, Rosenberg M, Corry D, et al. 2005. Assessing the relationship between concentrations of malodor compounds and odor scores from judges. J. Am. Dent. Assoc. 136: 749-757.

22. Lee EN, Sunwoo HH, Menninen K, Sim JS. 2002. In vitro studies of chicken egg yolk antibody (IgY) against Salmonella enteritidis and Salmonella typhimurium. Poult. Sci. 81: 623641.

23. Chen X, Yang B, Qi C, Sun TW, Chen F, Wu J, et al. 2016. DNA-templated microwave-hydrothermal synthesis of nanostructured hydroxyapatite for storing and sustained release of an antibacterial protein. Dalton Trans. 45: 16481656.

24. Cho E, Park SN, Lim YK, Shin Y, Paek J, Hwang CH, et al. 2015. Fusobacterium hwasookii sp. nov., isolated from a human periodontitis lesion. Curr. Microbiol. 70: 169-175. 
25. Tonzetich J. 1971. Direct gas chromatographic analysis of sulphur compounds in mouth air in man. Arch. Oral. Biol. 16: 587-597.

26. Yoshimura M, Nakano Y, Fukamachi H, Koga T. 2002. 3Chloro-DL-alanine resistance by L-methionine-alpha-deaminogamma-mercaptomethane-lyase activity. FEBS Lett. 523: 119122.

27. Suzuki N, Nakano Y, Watanabe T, Yoneda M, Hirofuji T, Hanioka T. 2018. Two mechanisms of oral malodor inhibition by zinc ions. J. Appl. Oral Sci. 26: e20170161.

28. Yoshida $\mathrm{Y}$, Ito $\mathrm{S}$, Kamo M, Kezuka $\mathrm{Y}$, Tamura $\mathrm{H}$, Kunimatsu K, et al. 2010. Production of hydrogen sulfide by two enzymes associated with biosynthesis of homocysteine and lanthionine in Fusobacterium nucleatum subsp. nucleatum ATCC 25586. Microbiology 156 (Pt 7): 2260-2269.

29. Liu J, Ling JQ, Wu CD. 2013. Cetylpyridinium chloride suppresses gene expression associated with halitosis. Arch. Oral Biol. 58: 1686-1691.

30. Amann A, Costello Bde L, Miekisch W, Schubert J, Buszewski B, Pleil J, et al. 2014. The human volatilome: volatile organic compounds (VOCs) in exhaled breath, skin emanations, urine, feces and saliva. J. Breath. Res. 8: 034001.

31. Oz HS, Puleo DA. Animal models for periodontal disease. 2011. J. Biomed. Biotechnol. 2011: 754857.
32. Oliveira GJ, Paula LG, Souza JA, Spin-Neto R, Stavropoulos A Marcantonio RA. 2017. Effects of avocado/soybean unsaponifiables (ASU) on the treatment of ligature-induced periodontitis in rats. Braz. Oral Res. 31: 1-11.

33. Yokoyama K, Sugano N, Shimada T, Shofiqur RA, Ibrahim el-SM, Isoda R, et al. 2007. Effects of egg yolk antibody against Porphyromonas gingivalis gingipains in periodontitis patients. J. Oral Sci. 49: 201-206.

34. Iwasaki Y, Otsuka H, Yanagisawa N, Hisamitsu H, Manabe A, Nonaka N, et al. 2011. In situ proliferation and differentiation of macrophages in dental pulp. Cell Tissue Res. 346: 99-109.

35. Mosser DM, Edwards JP. 2008. Exploring the full spectrum of macrophage activation. Nat. Rev. Immunol. 10: 958-969.

36. Grenier D, Mayrand D. 1985. Cytotoxic effects of culture supernatants of oral. bacteria and various organic. Can. J. Microbiol. 31: 302-304.

37. Tsuda H, Ochiai K, Suzuki N, Otsuka K. 2010. Butyrate, a bacterial metabolite, induces. apoptosis and autophagic cell death in gingival epithelial cells. J. Periodontal Res. 45: 626-634.

38. Kirschbaum M, Schultze-Mosgau S, Pfister W, Eick S. 2010. Mixture of periodontopathogenic bacteria influences interaction with KB cells. Anaerobe 16: 461-468.

39. Roberts GL. 2000. Fusobacterial infections: an underestimated threat. Br. J. Biomed. Sci. 57: 156-162. 